\title{
OPTIMIZATION OF THE INDICATIONS FOR SURGICAL TREATMENT AND CHOICE OF SURGERY VOLUME IN PATIENTS WITH NODULAR ENDEMIC GOITER AND AUTOIMMUNE THYROIDITIS
}

\author{
Michael I. SHEREMET ${ }^{1 凶}$, Larysa P. SYDORCHUK ${ }^{2}$, Viktor 0 . SHIDLOVSKYI ${ }^{3}$, \\ Oleksandr V. SHIDLOVSKYI ${ }^{3}$, Dragos CRETOIU ${ }^{4}$, Oleg V. TRIBUSHNYI ${ }^{5}$, Yan V. GYRLA ${ }^{1}$, \\ Oleksandr V. BILOOKYI ${ }^{1}$, Oleksandr V. LAZARUK ${ }^{6}$, Andryi I. POPOVYCH ${ }^{6}$, Oksana Y. OLINIK ${ }^{7}$, \\ Tetyana Y. LAZARUK ${ }^{7}$, Galyna Y. STELMAKH ${ }^{8}$ \\ ${ }^{1}$ Surgery Department №1, Bukovinian State Medical University, Chernivtsi, Ukraine \\ ${ }^{2}$ Family Medicine Department, Bukovinian State Medical University, Chernivtsi, Ukraine \\ ${ }^{3}$ Surgery Department, I. Horbachevsky State Medical University, Chernivtsi, Ukraine \\ ${ }^{4}$ Carol Davila" University of Medicine and Pharmacy, Bucharest, Romania \\ ${ }^{5}$ Department of Traumatology and Orthopedics, State Institution "Zaporizhzhia Medical Academy of \\ Post-Graduate Education of Health Ministry of Ukraine“, Zaporizhzhia, Ukraine \\ ${ }^{6}$ Department of Pathology, Bukovinian State Medical University, Chernivtsi, Ukraine \\ ${ }^{7}$ Department of Internal Medicine and Infectious Diseases, Bukovinian State Medical University, \\ Chernivtsi, Ukraine \\ ${ }^{8}$ Department of Human Anatomy named M.G. Turkevich, Bukovinian State Medical University, Chernivtsi, \\ Ukraine
}

Received 19 Febr 2021, Accepted 01 April 2021

hitps://doi.org/10.31688/ABMU.2021.56.2.11

\begin{abstract}
Introduction. The main treatment of autoimmune thyroiditis (AIT) is conservative. However, there are patients with AIT in whom surgical treatment is mandatory. The growing experience and reports of surgical intervention with newer indications challenges this traditional view of AIT.
\end{abstract}

The objective of the study was to determine the choice of surgery volume in patients with nodular goiter and AIT, taking into account the activity of

\section{Résumé}

Optimisation des indications de traitement chirurgical et choix du volume de chirurgie chez les patients atteints de goitre endémique nodulaire et de thyroidite autoimmune

Introduction. Le traitement principal de la thyroïdite auto-immune (TAI) est conservateur. Cependant, il existe des patients atteints de TAI pour lesquels un traitement chirurgical est obligatoire. Laugmentation de l'expérience et des rapports d'interventions 
apoptosis, index of proliferative activity and polymorphisms of cytotoxic T-lymphocyte antigen-4 (CTLA-4) gene.

Material and methods. 95 patients with nodular goiter and autoimmune thyroiditis (NGAIT) were included in the study. We determined the activity of the apoptosis index of proliferative activity and gene polymorphism of CTLA-4.

Results. The correlation analysis of markers used to optimize surgical treatment, namely the choice of the surgery volume in patients with NGAIT, showed that the studied tests are objective and reliable for the long-term results of surgical treatment: the volume of the thyroid gland not affected by the nodes less than $10 \mathrm{~cm}^{3}$, the level of antibodies to thyroid peroxidase (TPO $\mathrm{Ab}$ ) $<80.25 \mathrm{IU} / \mathrm{mL}$, the level of antibodies to thyroglobulin (TG Ab) $<89.34 \mathrm{IU} / \mathrm{mL}$, index of the immunoproliferative activity (IPA) $\mathrm{Ki}-67<10.55 \%$, index of immunoreactive cells (IIRC) Fas $>43 \%$, IIRC Bcl-2 <90\%, IIRC p $53>50 \%$; AA and AG-genotype of the CTLA-4 gene.

Conclusions. The study allowed to determine new criteria for selecting the volume of surgery in patients with NGAIT.

Keywords: nodular endemic goiter, autoimmune thyroiditis, CTLA-4 gene polymorphism, volume of surgery.

\section{List of abbreviations:}

AIT - autoimmune thyroiditis

NGAIT - nodular goiter with autoimmune thyroiditis

CTLA-cytotoxic T-lymphocyte antigen

TPO - thyroid peroxidase

TG - thyroglobulin

FNAB - fine needle aspiration biopsy

IPA - index of immunoproliferative activity

IIRC - index of immunoreactive cells

PCR - Polymerase chain reaction

\section{INTRODUCTION}

There are many studies of apoptotic processes in the pathogenesis of nodular goiter on the background of autoimmune thyroiditis (AIT) ${ }^{1-4}$. However, data about the markers involved in the regulation of apoptosis and proliferation in thyroid gland tissue in AIT are quite fragmented and sometimes contradictory, which requires some systematization, to optimize the diagnosis and prediction of nodular goiter on the background of AIT $^{5-7}$.

The chemical reagents used in the preparation of drugs for morphological studies by the standard method block most antigenic determinants. chirurgicales sur des indications plus récentes remet en question cette vision traditionnelle de TAI.

L'objectif de l'étude était de déterminer le choix du volume de chirurgie pour les patients atteints de goitre nodulaire et AIT, en tenant compte de l'activité d'apoptose, de l'indice d'activité proliférative et des polymorphismes du gène CTLA-4.

Matériel et méthodes. Nous avons examiné 95 patients atteints de TAI et goitre endémique nodulaire. Nous avons déterminé l'activité de l'indice d'apoptose, de l'activité proliférative et du polymorphisme génique du CTLA-4.

Résultats. Les analyses corrélatives des marqueurs que nous avons utilisés pour optimiser le traitement chirurgical, à savoir le choix du volume de chirurgie chez les patients atteints de TAI et goitre endémique nodulaire, ont montré que les tests étudiés sont objectifs et fiables par rapport aux résultats à long terme du traitement chirurgical: volume de la glande thyroïde non affectée par nodules $<10 \mathrm{~cm}^{3}$, le taux d'anticorps anti-TPO $<80,25 \mathrm{UI} / \mathrm{ml}$, le taux d'anticorps anti-TG $<89,34 \mathrm{UI} / \mathrm{ml}$, IPA Ki-67 < 10,55\%, IIRC Fas > 43\%, IIRC Bcl-2<90\%, IIRC p53>50\%, génotype AA et AG du gène CTLA-4.

Conclusions. L'étude a permis de déterminer de nouveaux critères de sélection du volume de la chirurgie chez les patients atteints de goitre nodulaire endémique et TAI.

Mots-clés: goitre nodulaire endémique, thyroïdite auto-immune, polymorphisme du gène CTLA-4, volume de la chirurgie.

Therefore, immunocytochemical and morphological studies of thyroid puncture material are performed on individual drugs, which leads to additional puncture biopsies and makes impossible the morphological identification of antibody-responsive cell $s^{8-12}$. The best option for preoperative cytological diagnosis of thyroid pathology is the sequential cytomorphological and immunocytochemical examination of the same smear of puncture material ${ }^{13-15}$.

Modest hypothyroidism is of little concern when treating a surgical patient; however, severe hypothyroidism can be a significant risk factor. Severe hypothyroidism can be diagnosed clinically by myxedema, as well as by slowness of affect, speech, and 
reflexes ${ }^{16-21}$. Circulating thyroxine and triiodothyronine values are low. The serum thyroid-stimulating hormone (TSH) level is high in all cases of hypothyroidism who are not caused by pituitary insufficiency, and it is the best test of thyroid function ${ }^{22-24}$. In the presence of severe hypothyroidism, both the morbidity and the mortality of surgery are increased, as a result of both anesthesia and surgery. These patients have a higher incidence of perioperative hypotension, cardiovascular complications, gastrointestinal hypomotility, prolonged anesthetic recovery, and neuropsychiatric disturbances ${ }^{24-27}$. They metabolize drugs slowly and are very sensitive to all medications. Therefore, when severe myxedema is present, it is preferable to defer elective surgery until a euthyroid state is achieved.

The objective of THE STUdY was to determine the volume of surgery in patients with nodular goiter on the background of AIT (NGAIT) taking into account the activity of apoptosis, proliferation, index of proliferative activity and polymorphisms of the gene of cytotoxic T-lymphocyte antigen-4 (CTLA-4) gene.

\section{Material AND MEthods}

95 patients with NGAIT, monitored between 6 months and 3 years, were included in the retrospective study. The patients were subdivided into two subgroups: subgroup 1 consisted of 68 patients with the single-nodular goiter and subgroup 2 consisted of 27 patients with multi-nodular goiter. The age of patients ranged from 18 to 45 years. The duration of the disease ranged from 1 to 20 years. The patients were examined in Chernivtsi Regional Endocrine Specialized Clinic (Ukraine) from May 5, 2016 to April 27, 2019.

The criteria for inclusion in the study were: age between $18-45$ years; verified diagnosis of thyroid adenoma, nodular endemic goiter on the background of AIT in the stage of euthyroidism or subclinical hypothyroidism; TSH level 0.4-4.0 MUn/mL, taking into account the dose of replacement therapy; thyroid peroxidase (TPO) antibodies (Ab) level 60-225.15 $\mathrm{IU} / \mathrm{mL}$; thyroglobulin (TG) Ab level 60.0-158.52 IU/ $\mathrm{mL}$; the volume of the node or nodes, according to thyroid ultrasound, from 2.25 to $7.55 \mathrm{~cm}^{3}$; birth and residence in a iodine deficient region; the patients' signed informed consent to be included in the study.

The exclusion criteria for all groups were: age less than 18 and more than 45 years; fibrous morphological variant of AIT; insufficient data for diagnosis; anamnestic data on acute bacterial or viral infections and vaccinations during the last six months; severe somatic pathology (diabetes, infection with human immunodeficiency virus, systemic autoimmune diseases, oncological diseases), use of immunosuppressive or immunostimulant drugs during the last year; pregnancy, lactation; refusal of the patient.

All patients were informed about the scope of the examinations and informed consents were signed.

The approval for this study was obtained from the Ethics Committee of the "Bukovinian State Medical University" and Chernivtsi Regional Endocrine Specialized Clinic, Ukraine (approval number 11-07.04.2016).

Patients from subgroup $1 \mathrm{did}$ not have a thyroid functional disorder, and according to ultrasound, the size of the remaining thyroid gland did not differ from preoperative measurements.

Patients from subgroup 2, according to ultrasound data after hemithyroidectomy, showed an increased volume of the remaining thyroid gland and the formation of a node or nodes on the background of severe lymphoid infiltration. The free T4 levels indicated moderate hypothyroidism.

In all the patients, ultrasound-controlled fine needle aspiration biopsy (FNAB) of the thyroid nodes was performed. At least three punctures of one node were made, based on the fact that the percentage of inadequate punctates decreases depending on the number of punctures: if one puncture is done, the percentage is $16 \%$, two punctures $-5.3 \%$, three punctures $-4 \%$, four punctures $-2.6 \%{ }^{10}$.

While preparing the smears, we used a method of restoration of antigen determinants activity developed and patented in the laboratory of the V.I. Komisarenko Endocrinology Institute, Ukraine. This method enables to combine cytomorphological and immunocytochemical data in one cytological preparation and provides a possibility to compare morphological and immunocytochemical characteristics of certain cellular elements ${ }^{29}$. The method gives good results on the drugs that were kept no more than three days after staining. After this period, the results were unstable, because of oxidization processes of some chemical compounds in the air ${ }^{9,12,13}$. To start an immunohistochemical reaction, monoclonal antibodies to the following antigens were used: Mouse Human Ki-67 FITC Clone MIB-1; Anti-p53 Protein Monoclonal Antibody, FITC Conjugated, Clone DO-7; Mouse Anti-Human Apoptosis Regulator Bcl-2 (BCL2) Monoclonal, Unconjugated, Clone 124 antibody; Mouse Anti-Human CD95 Monoclonal Antibody, Unconjugated, Clone FAS18; Mouse Anti-Human CD95L Monoclonal Antibody, Unconjugated, Clone NOK-1 by Dako Denmark A/S (Denmark).

The results of immunohistochemical reactions were evaluated by the semiquantitative analysis 
proposed by A.K. Khmelnytsky, according to color intensity: "+ -" small, "+" poor, "++" moderate, "+++" pronounced ${ }^{28}$.

The index of immunoreactive cells (IIRC) was calculated by the formula: (Fas, FasL, Bcl-2, P53) = N1/ $\mathrm{N} 2 \times 100 \%$, where N1 is the number of immunopositive cells to Fas, FasL, Bcl-2, P53 receptors, and N2 is the total number of the cellular nuclei per $1 \mathrm{~mm}^{2}$. The index of the immunoproliferative activity (IPA) was calculated by the formula: NKi67/N total $\times 100 \%$, where NKi67 is the total number of nuclei immunopositive for protein Ki67, $\mathrm{N}$ total is the total number of nuclei per $1 \mathrm{~mm}^{2}$. The morphometric analysis was performed with a microscope Bresser BioScience Bino (Germany), with a digital camera Nikon DS-Fil, and a personal computer with the software NIS-Elements F 3.2.

Genetic studies were performed in the Genetics Laboratory of "Nicolae Testemitanu" State University of Medicine and Pharmacy, Chisinau (Republic of Moldova). The deoxyribonucleic acid (DNA) was isolated from lymphocytes of venous whole blood. The venous blood was stored in test tubes, stabilized K2-EDTA. The isolation and purification of the DNA from the resulting material was carried out in accordance with the Thermo Scientific GeneJET Genomic DNA Purification kit manual \# K0721, Thermo Fisher Scientific. To standardize the conditions for the determination of polymorphisms, all samples were brought to a concentration of $2 \mathrm{ng} / \mu \mathrm{L}$, by DNA dilution in nuclease-free water.

Polymerase chain reaction (PCR) was performed in real-time (RT-PCR), using Taq DNA polymerase and specific primers and probes on QuantStudio 6 Applied Biosystems (USA), which allowed to obtain amplicons, to determine their number in real time, as well as to reduce the probability of diagnostic errors. The analysis of the data was carried out using the QuantStudio RealTime Software program (Fig. 1). The genotypes of analyzed polymorphism samples of rs 231775 of the CTLA4 rs17759659 gene is shown in Fig. 1.

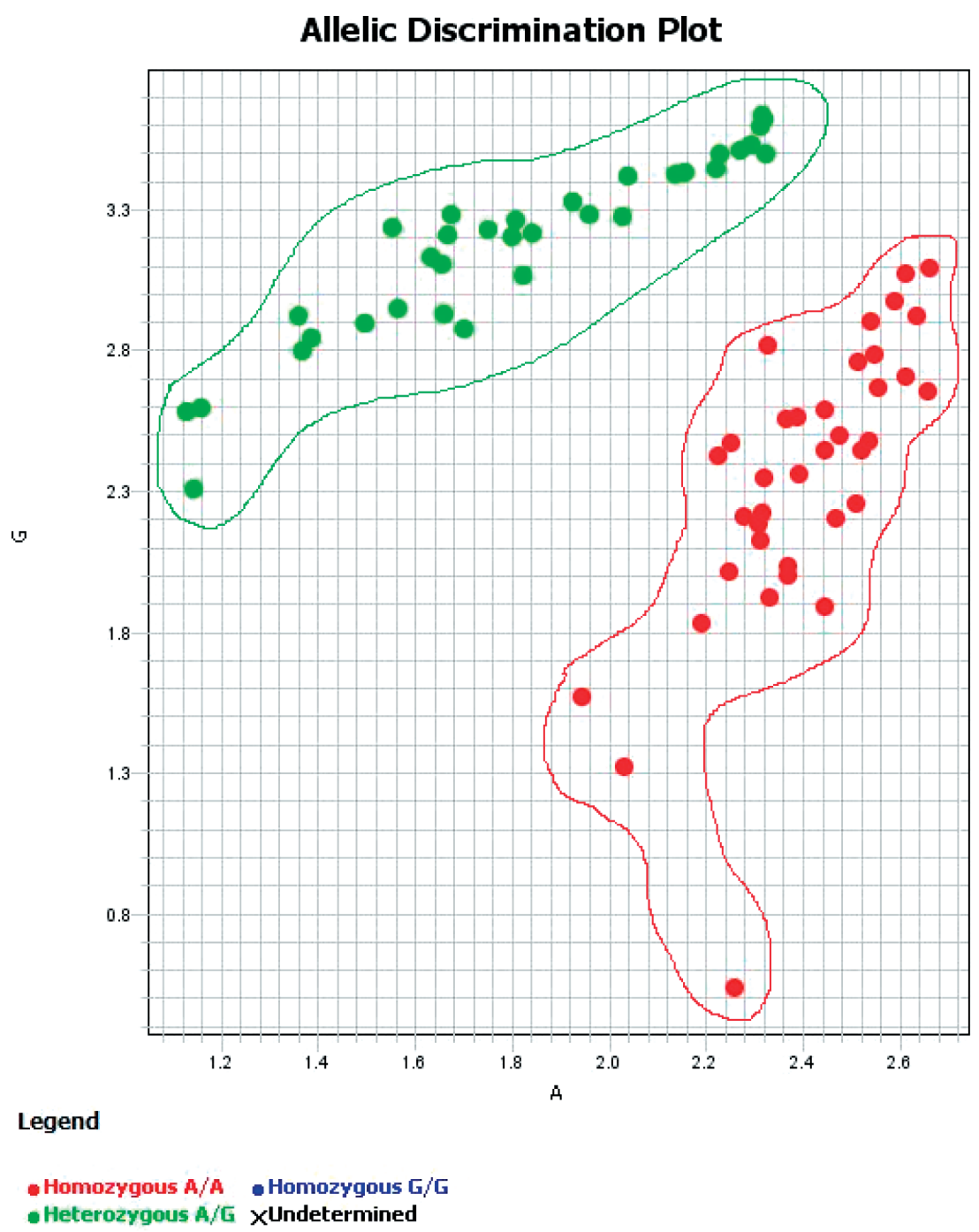

Figure 1. Discrimination of the alleles of rs 231775 CTLA4 (+49G/A) gene polymorphism 
The main part of the statistical analysis was performed using the program "Statistica 7.0" (SPSS). Nominal data are presented in the form of quantitative and percentage values. The correspondence of the genotype distribution to the Hardy-Weinberg ditch was checked using the Online Encyclopedia for Genetic Epidemiology Studies (http://www.oege. org/software/hwe-mr-calc.shtml). Pearson's c $c^{2}$ test was used to compare the distribution of genotypes in the experimental and control groups. The significance of differences in mean values in groups with different genotypes was determined using the method of one-way analysis of variance (ANOVA). The influence of factors on the development of thyroid pathology was evaluated using a model of binary logistic regression by relative risk (RelR), risk ratio (RR) and odds ratio (OR) with $95 \%$ confidence interval $[95 \%$ $\mathrm{CI}$, taking into account the criterion $\mathrm{c}^{2}(\mathrm{df}=1)$. The difference was considered significant at $\mathrm{p}<0.05$.

\section{Results AND DISCUSSION}

A retrospective comparison of ultrasound data, thyroid hormonal capacity, TPOAb and TGAb levels showed that patients from the first subgroup had a significantly lower preoperative volume of non-nodular lobe of the gland compared to patients from the second subgroup. The level of TPO Ab and TG Ab was significantly different and was higher in the second subgroup than in the first subgroup (Table 1).

A retrospective comparison of ultrasound data, thyroid hormonal capacity, TPO Ab and TG Ab levels, showed that in patients from the first subgroup, the preoperative volume of non-nodular lobe of the gland was significantly lower than in the second subgroup. The level of TPO Ab and TG Ab was significantly different, in the second subgroup was higher than in the first subgroup (Table 1).

The immunohistochemical examination of punctates of the remaining share in the two subgroups of patients revealed a significant suppression of apoptotic processes against the expressed activation of proliferative processes (Table 2). For replacement therapy, thyroxine preparations were used, in a dosage that maintained the TSH level between 0.4-4.0 MUn/ $\mathrm{mL}$. All patients received intravenously, 24 hours before surgery and daily after it (for 10 days), 300 IU of $\alpha$ - lipoic acid, then orally 300 IU per day for three months, with repeated use of tablets of $300 \mathrm{IU} /$ day for a month, every six months. This is a drug with antioxidant effect.

When comparing the indicators of proliferation and apoptosis, patients of the second subgroup had elevated IPA Ki-67, IIRC FasL, IIRC Bcl-2 and decreased IIRC Fas and IIRC p53 as compared to patients from the first subgroup (Table 2). A significant

Table 1. Comparative assessment of the volume and functional status of the thyroid gland before and after hemithyroidectomy for unilateral NGAIT.

\begin{tabular}{ccccc}
\hline \multirow{2}{*}{ Index } & \multicolumn{2}{c}{$\begin{array}{c}\text { First subgroup } \\
(\boldsymbol{n}=68)\end{array}$} & \multicolumn{2}{c}{$\begin{array}{c}\text { Second subgroup } \\
(\boldsymbol{n}=27)\end{array}$} \\
\cline { 2 - 5 } & before surgery & after surgery & before surgery & after surgery \\
\hline $\begin{array}{c}\text { Volume of the thyroid not af- } \\
\text { fected by the node }\left(\mathrm{cm}^{3}\right)\end{array}$ & $10.18 \pm 0.25$ & $9.27 \pm 0.23$ & $14.82 \pm 0.21$ & $20.86 \pm 1.17^{*}$ \\
\hline $\mathrm{Free} \mathrm{T}_{4}(\mathrm{pmol} / \mathrm{L})$ & $15.52 \pm 0.19$ & $13.8 \pm 0.19$ & $7.58 \pm 0.21^{*}$ & $5.83 \pm 0.46^{*}$ \\
\hline $\mathrm{TPO} \mathrm{Ab}(\mathrm{Un} / \mathrm{mL})$ & $73.21 \pm 0.19$ & $74.45 \pm 0.56$ & $114.44 \pm 1.15^{*}$ & $215.68 \pm 1.88^{*}$ \\
\hline $\mathrm{TG} \mathrm{Ab}(\mathrm{Un} / \mathrm{mL})$ & $73.15 \pm 0.49$ & $78.49 \pm 0.49$ & $106.23 \pm 1.23^{*}$ & $135.27 \pm 1.52^{*}$ \\
\hline & Note $^{*} \mathrm{p}<0.05$ probability coefficient between subgroups & \\
\hline
\end{tabular}

Table 2. Comparative evaluation of markers of proliferation and apoptosis in patients before and after hemithyroidectomy for unilateral NGAIT.

\begin{tabular}{ccccc}
\hline \multirow{2}{*}{ Index } & \multicolumn{2}{c}{$\begin{array}{c}\text { First subgroup } \\
(\mathbf{n = 6 8 )}\end{array}$} & $\begin{array}{c}\text { Second subgroup } \\
(\boldsymbol{n}=27)\end{array}$ \\
\cline { 2 - 5 } & before surgery & after surgery & before surgery & after surgery \\
\hline IPA Ki-67 (\%) & $8.45 \pm 0.22$ & $8.85 \pm 0.23$ & $10.91 \pm 0.24^{*}$ & $11.22 \pm 0.19^{*}$ \\
\hline IIRC Fas (\%) & $51.21 \pm 0.17$ & $55.63 \pm 0.27$ & $41.16 \pm 0.54^{*}$ & $39.93 \pm 1.63^{*}$ \\
\hline IIRC FasL (\%) & $41.71 \pm 0.19$ & $45.63 \pm 0.19$ & $56.17 \pm 0.76^{*}$ & $64.26 \pm 0.98^{*}$ \\
\hline IIRC Bcl-2 (\%) & $86.71 \pm 0.18$ & $90.64 \pm 0.17$ & $98.33 \pm 0.85^{*}$ & $97.41 \pm 1.86^{*}$ \\
\hline IIRC p53 (\%) & $66.13 \pm 0.15$ & $65.19 \pm 0.15$ & $54.72 \pm 0.61^{*}$ & $48.14 \pm 1.19^{*}$ \\
\hline & Note $^{*}-\mathrm{p}<0.05$ probability coefficient between subgroups & \\
\hline
\end{tabular}


Table 3. Discriminant Function Analysis Summary Wilks'-Lambda: 0.03051 approx. F =18.902, p<0.0000.

\begin{tabular}{ccccc}
\hline & \multicolumn{4}{c}{ Statistical indicators } \\
\cline { 2 - 5 } Investigated tests & 2 & 3 & 4 & p-value \\
\cline { 2 - 5 } & Wilks'-Lambda & Partial -Lambda & F-remove - (2.36) & 5 \\
\hline Volume of the thyroid gland & 0.074579 & 0.877086 & 16.1160 & 0.000107 \\
\hline FreeT4 & 0.065439 & 0.999591 & 0.0470 & 0.828762 \\
\hline TPO Ab & 0.070339 & 0.929952 & 8.6623 & 0.003931 \\
\hline TG & 0.083251 & 0.832651 & 8.1943 & 0.004122 \\
\hline Ki-67 & 0.157609 & 0.443281 & 23.2109 & 0.000000 \\
\hline Fas & 0.070541 & 0.927296 & 9.0165 & 0.003283 \\
\hline FasL & 0.065582 & 0.997420 & 0.2975 & 0.586519 \\
\hline Bcl-2 & 0.155692 & 0.420139 & 158.7192 & 0.000000 \\
\hline p53 & 0.149769 & 0.430213 & 144.4396 & 0.000000 \\
\hline AA genotype CTLA-4 gene & 0.069638 & 0.943298 & 8.593421 & 0.003983 \\
\hline AG genotype CTLA-4 gene & 0.073117 & 0.896572 & 8.762916 & 0.003629 \\
\hline
\end{tabular}

increase in the rates of proliferation and suppression of apoptosis detected long-term after the surgical treatment of NGAIT in patients of the second subgroup led to functional insufficiency and hyperplasia of the remaining part of the thyroid gland, and ultimately caused unsatisfactory results. Therefore, it is necessary to reconsider the choice of the volume of surgery in patients with NGAIT, depending on the severity of the autoimmune process and the functional capacity of the gland.

Thus, the retrospective analysis allows to differentiate the choice of the scope of the surgery, hemithyroidectomy or thyroidectomy, depending on the functional capacity of the thyroid gland and indicators of apoptosis and proliferation in the unaffected lobe of the gland. A comprehensive analysis of the studied indicators, with satisfactory and unsatisfactory long-term results of surgical treatment, allowed to establish the indicators that can predict a positive or negative long-term treatment outcome. On their basis, we have developed indications and contraindications to hemithyroidectomy and indications for thyroidectomy. When combining the studied indicators, the volume of unaffected thyroid lobe $<10 \mathrm{~cm}^{3}$, free T4 $>12.91 \mathrm{pmol} / \mathrm{L}, \mathrm{TPO} \mathrm{Ab}<80.25 \mathrm{IU} / \mathrm{mL}$ and $\mathrm{TG} \mathrm{Ab}<89.34 \mathrm{IU} / \mathrm{mL}$, with indicators of lymphoproliferative activity and apoptosis, in particular levels of IPA Ki-67<10.55\%, IIRC FasL 51\%, IIRC Bcl-2 $90 \%$, IIRC p53 >50\% and IIRC Fas > 43\% indicate hemithyroidectomy.

At the same time, when the volume of the thyroid gland not affected by nodes is $>10 \mathrm{~cm}^{3}$, free T4 $<12.91 \mathrm{pmol} / \mathrm{L}, \mathrm{TPO} \mathrm{Ab}>80.25 \mathrm{IU} / \mathrm{mL}$ and TG $\mathrm{Ab}>89.34 \mathrm{IU} / \mathrm{mL}$, with indicators of lymphoproliferative activity and apoptosis, in particular levels of IPA Ki-67 >10.55\%, IIRC FasL 51\%, IIRC Bcl-2
$90 \%$, IIRC p $53<50 \%$ and IIRC Fas $<43 \%$ indicate thyroidectomy.

The results of treatment in comparison with the polymorphism of the CTLA-4 gene were analyzed. It was found that in patients with wild A allele of the CTLA-4 gene (AA and AG genotypes) NGAIT was characterized by low proliferative activity (according to FNAB), absence of compression symptoms and a good effect of conservative treatment. The morpho-functional characteristics of the gland's tissue unaffected by nodes in patients with AA and AG genotypes made possible the utilization of active surgical tactics: hemithyroidectomy with postoperative drug treatment.

The share of homozygous GG genotype and polymorphic allele of the CTLA-4 gene in the group of patients with unsatisfactory results correlates with the hypertrophic form of AIT and the presence of nodes and pseudo-nodes, low apoptosis and pronounced proliferation. Carriers of the GG genotype of the CTLA-4 gene have III and IV risk categories according to the Bethesda classification. In such cases, the operation of choice is thyroidectomy.

To determine the volume of surgery in patients with NGAIT, we conducted a discriminant and correlation analysis of the studied tests, which characterize the positive long-term outcome of surgical treatment in these patients (Table 3).

\section{Conclusions}

In unilateral NGAIT with increased proliferation in the nodal tissue and low in the contralateral lobe, AA and AG genotype of the CTLA-4 gene, the operation of choice is hemithyroidectomy. In patients with unilateral NGAIT with pronounced 
proliferative activity in the tissue of the contralateral lobe, GG-genotype of the CTLA-4 gene, the operation of choice is thyroidectomy.

As contraindications of hemithyroidectomy in patients with NGAIT can be considered the volume of unaffected thyroid nodules $>10 \mathrm{~cm}^{3}$, free T4 $<12.91$ $\mathrm{pmol} / \mathrm{L}, \mathrm{TPO} \mathrm{Ab}>80.25 \mathrm{IU} / \mathrm{mL}, \mathrm{TG} \mathrm{Ab}>89.34 \mathrm{IU} /$ $\mathrm{mL}$, IPA Ki-67 >10.55\%, increase in FASL $>51 \%$, increase in $\mathrm{Bcl}-2>90 \%$, decrease in IIRC Fas $<43 \%$ and IIRC p $53<50 \%$, GG-genotype of the CTLA-4 gene. In these patients, thyroidectomy is preferred.

\section{Author Contributions:}

Conceptualization, M.I.S., L.P.S.; methodology, O.V.S.; software, D.C.; validation, O.V.T., O.V.L.; formal analysis, Y.V.G., O.V.B.; investigation, A.I.P.; resources, V.O.S.; data curation, M.I.S. and O.Y.O.; writing-original draft preparation, O.V.L..; writing-review and editing, Y.V.G., O.V.T., T.Y.L.; visualization, L.P.S. and G.Y.S.; supervision, D.C.; project administration, M.I.S.. All the authors have read and agreed with the final version of the article.

\section{Compliance with Ethics Requirements:}

"The authors declare no conflict of interest regarding this article"

"The authors declare that all the procedures and experiments of this study respect the ethical standards in the Helsinki Declaration of 1975, as revised in 2008(5), as well as the national law. Informed consent was obtained from all the patients included in the study"

"No funding for this study"

\section{Acknowledgements:}

None

\section{References}

1. Sheremet MI, Sydorchuk LP, Shidlovskyi VO, Bedenyuk AD. Research of prognostic markers of proliferation and apoptosis in patients with nodular goiters combined with autoimmune thyroiditis. Arch Balk Med Union 2016;51(4): 488-91.

2. Kazakov SP, Kushlinsky NY. The investigation of CD 95, P53, BCL-2 and $\mathrm{Ki}-67$ markers in autoimmune thyroid pathology patients. First Joint Meeting of European National Societies of Immunology Under the auspices of EFIS and 16th European Congress of Immunology: ECI. 2006; Sept. 6-9, Paris, France: 547.

3. Sheremet MI, Sydorchuk LP, Shidlovskyi VO, Bedenyuk AD, Popovych AI, Lazaruk OV. Fine needle biopsy in differential diagnosis of nodular goiter with autoimmune thyroiditis and differentiated thyroid cancers. Journal of Education, Health and Sport 2017; 7(4):701-6.

4. Sheremet MI, Sydorchuk LP, Shidlovskyi VO, et al. Remote results of hemithyroidectomy and their prognostication in patient with unilateral nodular goiter combined with autoimmune thyroiditis. Arch Balk Med Union 2018;53(1): 41-6.

5. Wienhold R, Scholz M, Adler JR, et al. The management of thyroid nodules: a retrospective analysis of health insurance data. Dtsch Arztebl Int. 2013;110(49): 827-34.

6. Sheremet MI, Sydorchuk LP, Shidlovskyi VO, et al. Influence of the CTLA-4 (rs231775) gene polymorphism on the degree of the thyroid gland enlargement in patients operated for nodular goiter secondary to autoimmune thyroiditis. Arch Balk Med Union 2017; 52(4):384-90.

7. Ahn HS, Kinm HJ, Welch HG, et al. Korea's thyroid cancer epidemic-screening and overdiagnosis. N Engl J Med 2014;371(19):1765-67.

8. Diaconescu MR, Glod M, Costea I, Grigorovici M, Diaconescu S. Indications for surgery in thyroiditis. Chirurgia (Bucur). 2012;107(3):337-42.

9. Erdal M, Sahin M, Hasimi A, Uckaya G, Kutlu M, Saglam K. Trace element level-s in Hashimoto's thyroiditis patients with subclinical hypothyroidism. Biol Trace Elem Res. 2008;123(1-3):1-7.

10. Nakahara M, Nagayama Y, Saitoh O, et al. Expression of immunoregulatory molecules by thyrocytes protects nonobesediabetic-H2h4 mice from developing autoimmune thyroiditis. Endocrinol. 2009;150(3):1545-1551.

11. Ganesh BB, Bhattacharya P, Gopisetty A, Prabhakar BS. Role of cytokines in the pathogenesis and suppression of thyroid autoimmunity. Journal of Interferon $\mathcal{E}$ Cytokine Research 2011;31(10): 721-31.

12. Guan LJ, Wang X, Meng S, et al. Increased IL-21/IL-21R expression and its proinflammatory effects in autoimmune thyroid disease. Cytokine 2015; 72(2): 160-5.

13. Sheremet MI, Shidlovskyi VO, Sydorchuk LP. Assessment of proliferation and apoptosis markers in patients with autoimmune thyroiditis. Journal of Education, Health and Sport 2016;6(1):179-188.

14. Rautureau GJ, Day CL, Hinds MG. Intrinsically disordered proteins in bcl-2 regulated apoptosis. Int J Mol Sci 2010;11(4):1808-24.

15. Kinnally KW, Antonsson B. A tale of two mitochondrial channels, MAC and PTP, in apoptosis. Apoptosis 2007;12(5):857-68.

16. Erdamar H, Demirci H, Yaman H, et al. The effect of hypothyroidism, hyperthyroidism, and their treatment on parameters of oxidative stress and antioxidant status. Clin Chem Lab Med. 2008;46(7):1004-10.

17. Chen AY, Bernet VJ, Carty SE, Davis TF, Ganky I, Inabnet WB III, Shaha AR. American Thyroid Association statement on optimal surgical management of goiter. Thyroid 2014; 24:181-89.

18. Randolph GW, Dralle $\mathrm{H}$, Abdullah $\mathrm{H}$, et al. Electrophysiologic recurrent laryngeal nerve monitoring during thyroid and parathyroid surgery: international standards guideline statement. Laryngoscope 2011; 121(Suppl 1):S1-16.

19. Chen Y, Sadow PM, Suh H, Lee KE, Choi JY, Suh YJ, Wang TS, Lubitz CC. BRAF (V600E) is correlated with recurrence of papillary thyroid microcarcinoma: a systematic review, multi-institutional primary data analysis, and meta-analysis. Thyroid 2016; 26(2):248-55.

20. Cho JW, Lee YM, Lee YH, Hong SJ, Yoon JH. Dynamic risk stratification system in post-lobectomy low-risk and intermediate-risk papillary thyroid carcinoma patients. Clinical Endocrinology 2018; 89(1):100-109.

21. Haugen BR, Alexander EK, Bible KC, et al. Thyroid Association management guidelines for adult patients 
with thyroid nodules and differentiated thyroid cancer: the American Thyroid Association Guidelines Task Force on Thyroid Nodules and Differentiated Thyroid Cancer. Thyroid. 2016;26(1):1-133.

22. Lee YM, Lee YH, Song DE, et al. Prognostic impact of further treatments on distant metastasis in patients with minimally invasive follicular thyroid carcinoma: verification using inverse probability of treatment weighting. World Journal of Surgery 2017;41:138-145.

23. Lee YM, Park JH, Cho JW, Hong SJ, Yoon JH. The definition of lymph node micrometastases in pathologic N1a papillary thyroid carcinoma should be revised. Surgery 2019; 165(3):652-656.

24. Lubitz CC, Economopoulos KP, Pawlak AC, et al. Hobnail variant of papillary thyroid carcinoma: an institutional case series and molecular profile. Thyroid 2014;24(6):958-965.
25. Nath MC, Erickson LA. Aggressive variants of papillary thyroid carcinoma: hobmail, tall cell, columnar, and solid. Advances in Anatomic Pathology 2018;25(3):172-179.

26. Song E, Jeon MJ, Oh HS, et al. Do aggressive variants of papillary thyroid carcinoma have worse clinical outcome than classic papillary thyroid carcinoma? European Journal of Endocrinology 2018;179(3):135-142.

27. Wreesmann VB, Nixon I J, Rivera M, et al. Prognostic value of vascular invasion in well-differentiated papillary thyroid carcinoma. Thyroid 2015;25(5):503-508.

28. Khmelnitsky DC. Cytological and histological diagnosis of thyroid diseases: a guide. St. Petersburg, 2002:288.

29. Nikonenko AG, Bozhok YM. Patterns of papillary thyroid carcinoma cells analyzed in fine-needle aspiration smears may reveal changes in tumor cell behavior. Diagnostic Cytopathology 2012;40 Suppl 1:E55-61. 